\title{
Особенности коммуникативного поведения в интернет-пространстве подростков с разными типами суицидального поведения
}

\author{
Анжелика И. Лучинкина“, Ирина С. Лучинкина \\ Крымский инженерно-педагогический университет, г. Симферополь, Российская \\ Федерация \\ *E-mail: a.luchinkina@kipu-rc.ru
}

\begin{abstract}
Аннотация
Введение. В статье приводится анализ суицидального поведения подростков в зависимости от выраженности у них определенных когнитивных искажений. В работе впервые приводятся Аанные стандартизации опросника, выявляющего когнитивные искажения ^ичности. Несомненной научной новизной является тот фракт, что выраженное суицилальное поведение полростков Аетерминировано социально-психологическими причинами. Авторами теоретически Аоказаны и эмпирически выявлены четыре типа суициАального поведения Аичности в интернет-пространстве. Авторами анализируются групповые и индивидуальные когнитивные механизмы, вкАючающие тот или иной тип суициАального повеАения мичности в интернет-пространстве.
\end{abstract}

Методы. В эмпирическом исслеАовании приняли участие поАростки, имеющие низкий социометрический статус в школьных группах и посещающие группы с суициАальным контентом в интернет-пространстве. Использовались теоретический анализ, контент-анализ, анкетирование, психодиагностическое тестирование, в том числе и авторские исслеАовательские опросники.

Результаты. В холе исслеАОвания поАростки были отнесены к группам с разными типами суициАального поведения: суициАентов, имитаторов, хуАожников, зрителей. Эмпирически выявлено, что наиболее часто встречающиеся в выборке групповые когнитивные механизмы - ил^юзорная корреляция, искажение в оценке гомогенности группы, групповая поляризация и предвзятость подтвержАения. Наиболее распространенными инАивиАуальными когнитивными механизмами оказались дихотомическое мышление, катастрофризация, персонализация, обесценивание позитивного, эмоциональное обоснование и навешивание ярлыков.

ОбсужАение результатов. Эмпирически определены различия в выборе поАростками групповых и инАивиАуальных когнитивных механизмов коммуникации в зависимости от группы суицилального поведения. ПреАложена программа когнитивной коррекции Аля кажАой из вылеленных групп, в связи с тем, что Аругие методы показали свою несостоятельность. 


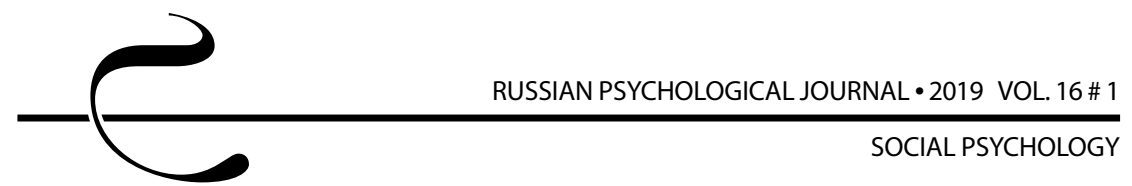

\title{
КАючевые слова
}

групповые когнитивные механизмы, индивидуальные когнитивные механизмы, типы суициАального поведения, подростки, интернет-пространство, суициАенты, когнитивные ошибки, виктимность, социометрический статус, коррекция

\section{Основные положения}

- в основе суицилального поведения личности лежат 4 фрактора: поведение жертвы; непризнанность - Аемонстративность, несостоятельность, уникальность; героизация смерти - слом культурных барьеров, вовлеченность в интернет-пространство; негативность мира - социальный пессимизм, направленность Аеятельности в интернет-пространстве;

- вес кажАого из факторов позволяет вылелить 4 типа суициАального повеАения: суициАенты, имитаторы, хуАожники, зрители;

- существует устойчивая взаимосвязь межАу типом суициАального повеАения мичности в интернет-пространстве и выраженностью ее когнитивных искажений; - существуют Аостоверные различия в выборе групповых и индивидуальных коммуникативных механизмов коммуникации у представителей разных типов суициАального повеАения.

\section{Для цитирования}

Лучинкина А. И., Лучинкина И. С. Особенности коммуникативного поведения в интернет-пространстве подростков с разными типами суицидального поведения // Российский психологический журнал. 2019. Т. 16, № 1. С. 128-143. DOI: 10.21702/ rpj.2019.1.6

Материалы статьи получены 27.08.2018

UDC 316.6:159.9.072.43

DOI: $\underline{10.21702 / r p j .2019 .1 .6}$

\section{Characteristics of Communicative Behavior on the Internet Among Adolescents with Different Suicidal Behaviors}

\section{Anzhelika I. Luchinkina*, Irina S. Luchinkina}

Crimean Engineering and Pedagogical University, Simferopol, Russian Federation * Corresponding author. E-mail: a.luchinkina@kipu-rc.ru

\begin{abstract}
Introduction. Adolescent suicidal behavior is determined by socio-psychological factors. This study aims to analyze suicidal behavior among adolescents depending on their cognitive distortions and represents the first attempt to present standardization
\end{abstract}


data on the cognitive distortions questionnaire. The authors (a) describe four suicidal behaviors on the Internet, (b) analyze group and individual cognitive mechanisms that determine these suicidal behaviors on the Internet.

Methods. The empirical study involved adolescents with low sociometric statuses in their school groups, who visited the social networking groups containing suicidal content. Theoretical analysis, content analysis, questionnaire survey, and psychodiagnostic tests, including the questionnaires developed by the authors, were employed in the study. Results. According to different suicidal behaviors the authors distinguished the following groups among the surveyed adolescents: suiciders, imitators, artists, and spectators. Illusory correlation, distortion in the evaluation of group homogeneity, group polarization, and confirmation bias were the most common group cognitive mechanisms in the whole sample. Dichotomous thinking, catastrophizing, personalization, devaluation of positive events, emotional reasoning, and stigmatization were the most common individual cognitive mechanisms.

Discussion. The findings of the study suggest that the group of suicidal behaviors determine the differences in adolescents' choice of group and individual cognitive mechanisms of communication. Because of invalidity of other techniques, the authors propose a program of cognitive correction in each of the distinguished groups.

\section{Keywords}

group cognitive mechanisms, individual cognitive mechanisms, suicidal behaviors, adolescents, Internet, suiciders, cognitive errors, victimization, sociometric status, correction

\section{Highlights}

- The following four factors underlie suicidal behaviors: (a) victim behavior; (b) nonrecognition - demonstrativeness, failure, and uniqueness; (c) heroization of death breaking down cultural barriers, Internet involvement; and (d) negativity of the world social pessimism, orientation of activities in the Internet.

- The factors mentioned above enabled authors to distinguish among four suicidal behaviors - suiciders, imitators, artists, and spectators.

- There is an association between adolescents' suicidal behaviors on the Internet and their cognitive distortions.

- There are significant differences in the choice of group and individual communication mechanisms among representatives of different suicidal behaviors.

\section{For citation}

Luchinkina A. I., Luchinkina I. S. Characteristics of Communicative Behavior on the Internet Among Adolescents with Different Suicidal Behaviors. Rossiiskii psikhologicheskii zhurnal - Russian Psychological Journal, 2019, V. 16, no. 1, pp. 128-143 (in Russian). DOI: 10.21702/rpj.2019.1.6

Original manuscript received 27.08.2018 


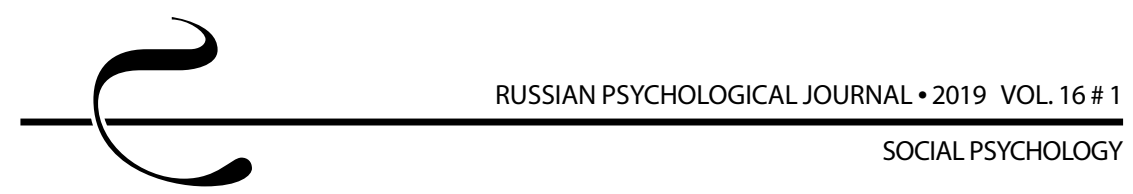

\section{Введение}

Небывалая активизация интереса интернет-пользователей к виртуальным группам смерти, мифологизации мышления, и связанная с этим героизация смерти ставят перед исследователем задачу поиска как индивидуальных, так и общих причин суицидального поведения подростков. Научная проблема исследования заключается в выявлении механизмов, характерных для разных типов суицидального поведения личности.

В психологической литературе суицидальное поведение изучалось в разных аспектах: возрастная динамика суицидов (А. Г. Абрумова, К. С. Веселовский) [1, 2, 3, 4]; акцентуации и психические расстройства (А. Е. Личко, А. А. Александров) $[5,6] ;$ межличностные отношения со сверстниками и родителями (Л. Я. Жезлова) [7]; влияние подростковых субкультур на суицидальные намерения подростков; типология подростковых суицидов (Е. М. Вроно, Н. А. Ратинова и др.) $[8,9,10,11]$, влияние воспитания на формирование суицидальных наклонностей (В. М. Бехтерев и И. А. Сикорский, М. И. Гернет, А. Ф. Кони, П. А. Сорокин) [3]; суицидальное поведение как молодежная девиация (Ю. А. Клейберг, В. А. Шапинский, А. И. Ковалева) [12, 13]. Несмотря на высокую научную активность в этом направлении, психологические механизмы, характерные для разных типов суицидального поведения личности, остались малоизученными.

Учитывая, что эмоционально-поведенческие реакции личности не являются непосредственными ответами на внешние стимулы, а обрабатываются и интерпретируются, исходя из особенностей внутренней когнитивной системы, отметим основные когнитивные искажения личности, проявляющиеся на индивидуальном уровне: произвольное умозаключение, селективность внимания, сверхобобщение, преувеличение/преуменьшение, персонализация, дихотомическое мышление, катастрофизация, излишняя ответственность.

Для нашего исследования выберем следующие индивидуальные когнитивные механизмы [14, 15, 16]: 1) дихотомическое мышление; 2) катастрофизацию; 3) обесценивание позитивного; 4) эмоциональное обоснование, убеждение, что нечто должно быть правдой только потому, что вы «чувствуете» (по сути, верите) в это настолько сильно, что игнорируете или обесцениваете доказательства обратного; 5) навешивание ярлыков; 6) мысленный фильтр (избирательное абстрагирование); 7) чтение мыслей; 8) персонализацию - представление о себе как о причине негативного поведения других; 9) долженствование (мышление в стиле «я должен»); 10) сверхгенерализацию.

Кроме того, стоит отметить групповые когнитивные механизмы, проявляющиеся в формах восприятия информации $[17,18,19,20]$ :

1. Групповая поляризация-расхождения мнений интернет-пользователей в ходе дискуссии [21, 22]. 
2. Иллюзорная корреляция - восприятие интернет-пользователями преувеличенно тесной взаимосвязи между какими-либо значениями или событиями, которой в реальности не существует, либо значительно меньше, чем предполагают участники интернет-дискуссии (например, приписывание группе этнического меньшинства отрицательных качеств).

3. Искажение в оценке гомогенности членов другой группы-приписывание социокультурной группе определенных качеств, попытки обосновать свою точку зрения; искажение в пользу своей группы; искажение переноса; склонность к подтверждению, интерпретация информации с целью подтвердить свое мнение, адаптация информации для подтверждения своих убеждений; отклонение в сторону позитивного исхода.

4. Предвзятость подтверждения - принятие или непринятие логической силы аргумента в ходе интернет-дискуссии в зависимости от веры в истинность или ложность заключения; фрейминг; ретроспективное искажение [19, 23, 24].

\section{Авторская типология суицидального поведения подростков}

В целом, под суицидальным поведением мы будем понимать любые действия, в основе которых лежат представления о лишении себя жизни [25]. В наших более ранних исследованиях мы отмечали, что суицидальная личность в виртуальном пространстве включает следующие составляющие: когнитивную - убеждения и уровень инструментальной компетентности личности, мифологическую - личные мифологемы подростков, мотивационную - мотивы нахождения в Сети. В качестве дополнительных переменных нами был принят социально-психологический статус подростка в группе сверстников и уровень виктимности.

Согласно проведенным исследованиям, нами были выделены 4 фактора суицидального поведения подростков [26, 27]:

1. Фактор А: поведение жертвы.

2. Фактор В: непризнанность - демонстративность, несостоятельность, уникальность.

3. Фактор С: героизация смерти - слом культурных барьеров, вовлеченность в интернет-пространство.

4. Фактор D: негативность мира - социальный пессимизм, направленность деятельности в интернет-пространстве.

Вес факторов и выраженность когнитивной, мифологической и мотивационной составляющих позволил выделить 4 типа суицидального поведения подростков [26, 27, 28]:

1. Имитаторы - подростки с преобладанием факторов поведения жертвы (A) и негативности мира (D). Основная личная мифологема: арлекин. Основной мотив деятельности в интернет-пространстве - репликация 
в девиантной форме реализации, что приводит к тиражированию своих страниц в интернет-пространстве и ведению асоциальной деятельности [26].

2. Суициденты - подростки с преобладанием факторов А и С. Основная личная мифологема: пустое место. Основной мотив - мотив воплощения в роль героя суицидальной направленности, что мешает жизнедеятельности в реальном пространстве [26].

3. Художники - подростки с ведущими факторами А и В. Основная личная мифологема: жертва. Основной мотив - взнос в девиантной форме реализации [26].

4. Зрители - подростки, у которых ни один из факторов не выражен. Основная личная мифологема: путник. Основной мотив - нормативные потребительские и творческие мотивы (личного пространства, взноса, воплощения в роль, репликации) $[26,28]$.

Целью эмпирического исследования стало выявление коммуникативных психологических механизмов у подростков с разными типами суицидального поведения.

\section{Методы}

Использовались теоретический анализ, констатирующий эксперимент. На этапе констатирующего эксперимента для выявления типов суицидального поведения подростков применялся опросник А. И. Лучинкиной «Типология суицидального поведения подростков» (ТСПП); для выявления индивидуальных когнитивных искажений - опросник И. С. Лучинкиной «Когнитивные ошибки в ходе интернет-общения» (ОКИ); для выявления групповых когнитивных искажений - контент-анализ текстов в социальных сетях [26, 29, 30].

Опросник «Типология суицидального поведения подростков» включал в себя 20 вопросов, отнесенных к четырем моделям суицидального поведения подростков. Вопросы направлены на выявление мотивов деятельности в интернет-пространстве, когнитивных установок, личных мифологем подростков, их отношения к смерти, к себе самому и к миру в целом. Любой вопрос предполагал 4 варианта ответов, каждый из которых соответствовал выделенным моделям суицидального поведения [26].

Опросник И. С. Лучинкиной «Когнитивные искажения в ходе интернет-общения» (ОКИ) разработан на основе когнитивно-поведенческой теории психологов и психотерапевтов А. Бека и Д. Бек для выявления доминирующих когнитивных искажений в психике (дихотомического мышления, катастрофизации, обесценивания позитивного, эмоционального обоснования, навешивания ярлыков, мысленного фильтра, чтения мыслей, персонализации, долженствования, сверхгенерализации). Опросник содержит 40 вопросов, каждый из которых имеет 3 варианта ответов. Все вопросы распределены 
по 10 шкалам и направлены на выявление соответствующего когнитивного искажения [29].

\section{Экспериментальная база исследования}

В эмпирическом исследовании приняли участие 811 подростков 8-10 классов средних образовательных учреждений г. Симферополь Республики Крым, состоящих или неоднократно посещающих виртуальные группы с суицидальным контентом и имеющих низкий социометрический статус в классе. Среди них было 456 девочек и 355 мальчиков. Подростки, которые не проявляли интерес к группам с суицидальным контентом, к исследованию не привлекались. Исследование проходило в рамках работы экспериментальных площадок по профилактике суицидального поведения детей и подростков, организованной кафедрой психологии Государственного бюджетного образовательного учреждения высшего образования Республики Крым «Крымский инженерно-педагогический университет».

\section{Этапы эксперимента}

Констатирующий эксперимент включал в себя два этапа. На первом этапе при помощи опросника А. И. Лучинкиной «Типология суицидального поведения подростков» (ТСПП) нами были определены типы суицидального поведения подростков. На втором этапе при помощи опросника И. С. Лучинкиной «Когнитивные ошибки в ходе интернет-общения» (ОКИ) и контент-анализа текстов в социальных сетях выявлены когнитивные искажения, характерные для каждого типа суицидального поведения подростков $[26,29]$.

\section{Результаты}

По результатам исследования выявлены 4 группы подростков, имеющие отличия в уровнях виктимности, суицидальных рисков, личной мифологемы, мотивации деятельности в интернет-пространстве: суициденты (67 человек); имитаторы (148 человек); художники (218 человек); зрители (378 человек).

Анализ частоты встречаемости тех или иных когнитивных механизмов группового коммуникативного поведения показал, что респонденты, отнесенные к группе «суициденты», склонны к фреймингу, предвзятости подтверждения. В комментариях респондентов этой группы самоубийство связывается со смелостью, любовь - с несчастьем, ссора - со смертью.

В исследуемом массиве из 1000 сообщений нами было выделено 321 послание с нарушенной причинно-следственной связью на тему смерти. 218 сообщений принадлежат респондентам группы «суициденты». Другим групповым когнитивным механизмом для «суицидентов» является искажение в оценке гомогенности членов другой группы. Так, оценивая преимущества 


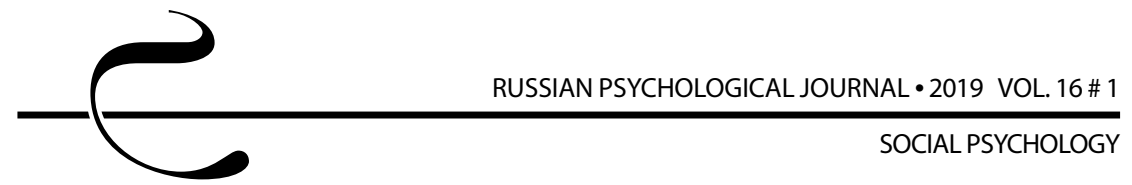

группы с суицидальным контентом, респонденты отмечают, что «остальные их не понимают, в мире отсутствуют любовь и уважение, только эта группа способна понять личность». Респонденты этой группы часто прибегают к фреймингу - «передергиванию» событий, что ведет к их неправильному восприятию (рисунок 1).

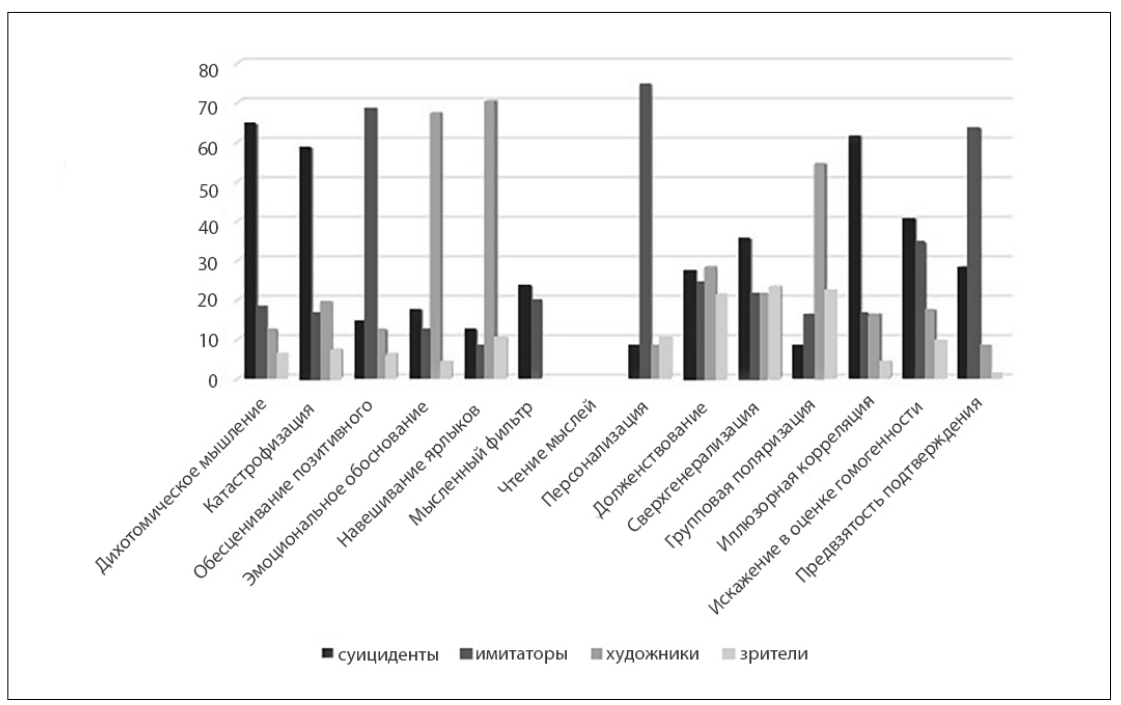

Рисунок 1. Распределение групповых и когнитивных механизмов по типам суициАального повеАения

Figure 1. Distribution of group and cognitive mechanisms by suicidal behaviors

Следует отметить, что у данного типа респондентов выражены все типы индивидуальных когнитивных искажений, но значительно преобладают дихотомическое мышление и катастрофизация ( $p \leq 0,05)$. В 96 \% случаев респонденты этой группы выбирают ответ «а» в опроснике «Когнитивные ошибки в ходе интернет-общения» при ответе на вопросы по шкалам «дихотомическое мышление» и «катастрофизация»:

«Что Вы думаете (что бы Вы подумали), находясь в интернет-пространстве, когда...

1. ...между Вами и Вашим оппонентом возникает спорный диалог?

а) если я не выиграю данный спор и не докажу свою правоту, то проиграю и покажу, что я слабый;

2. ...видите в комментариях интернет-группы групповую «травлю» какого-то пользователя? 
а) я так расстроюсь, что буду очень долго переживать и с трудом выполнять какие-либо действия;

11....кто-то пишет оскорбительные комментарии под Вашими фотографиями?

а) мне будет очень стыдно и обидно знать, что кто-то считает меня некрасивым/неумным/глупым, моя самооценка от этого может пострадать;

12. ...увидите информацию о животных, которые стали жертвами плохих хозяев?

а) это мерзко, ужасно и больно читать такие посты, я боюсь жить в таком ужасном мире!

21....видите, что в интернет-группе высмеивают человека Вашего пола/ национальности/расы с помощью интернет-мемов?

а) это прямое оскорбление и унижение. Там, где высмеивают людей по указанным признакам - гнилое общество и отсутствие толерантности;

22. ... читаете посты о произошедших пожарах?

а) мне становится страшно и опасно, так как помещения часто бывают непроверенные, проводка неисправная, а знания техники безопасности нагоняют ужас!

31. ...если Вас кто-то из хорошо знакомых людей (одногрупников, коллег и т. д.) удалит из друзей без всяких причин?

а) если удалил из друзей, значит, хорошим отношениям конец, и я буду напряженно относиться к данному человеку;

32. ... кто-то в общем диалоге начнет критиковать или негативно комментировать Вас и Ваши сообщения?

а) это очень неприятно и ужасно. Я так расстроюсь, что не смогу вообще ничего делать».

В группе «имитаторы» наиболее выраженными являются такие групповые механизмы, как искажение в оценке гомогенности членов другой группы, склонность к подтверждению, ретроспективное искажение. В групповых сообщениях, комментариях к фотографиям респонденты этой группы используют приписывание своей группе и своим убеждениям особый смысл: смерть решает все проблемы; только тот, кто может умереть, понимает смысл жизни. При этом другим группам отводится роль неполноценных «прожигателей» жизни.

Среди индивидуальных когнитивных механизмов наиболее часто встречаются обесценивание позитивного и персонализация ( $\leq \leq 0,05)$. При этом в $87 \%$ случаев респонденты выбирают ответы «а» по следующим вопросам:

«Что Вы думаете (что бы Вы подумали), находясь в интернет-пространстве, когда...

3. ...кто-то из неизвестных Вам интернет-пользователей оценил лайком и позитивным комментарием Вашу фотографию? 
а) действительно, эта фотография удачная, но она не говорит о моей красоте и приятной внешности в целом;

8. ...диалог в личной переписке крайне скудный и вялый?

а) диалог был скудный и вялый, значит, я был недостаточно хорошим собеседником и плохо выстраиваю контакт;

13. ... кто-то из незнакомых Вам интернет-пользователей оценит Ваш пост или комментарий в интернет-сообществе лайком и позитивной обратной связью («Какой интересный и глубокий комментарий, сразу видно, -умный человек!»)?

а) соглашусь, этот комментарий хороший, но я не всегда могу писать подобные, так что «умный человек» - относительно поспешный вывод;

18. ... Вы написали свое мнение в комментариях (без критики, троллинга и издевок), а Вам в ответ написали, что Вы своими словами кого-то обидели?

а) если мои слова кого-то обидели или зацепили, значит, я недостаточно толерантен и отзывчив, мне нужно контролировать свои комментарии;

23. ... люди восторгаются Вашим профилем в социальной сети (Вконтакте, Facebook, Instagram и пр.)?

а) страница, действительно, хорошая, но едва ли она была такой без фильтров, красивых фотографий (природы, еды и др.) и фотошопа;

b) мне приятно, что оценили мои старания, но есть и более идеальные страницы;

с) ничего не думаю (мне приятно);

24. ...на Вас подписалось достаточно большое количество человек?

а) я понимаю, что моя интернет-популярность растет, но я продолжаю ощущать свою страницу недостаточно хорошей и интересной для других людей;

28. ... Вы написали пост о том, что внешность - показатель внутренней гармонии, а Вас обвинили в оскорблении бодипозитивных идей?

а) действительно, я не подумал о том, что мои размышления о внешности не должны задевать других людей, я ни в коем случае не хотел своим постом кого-либо обидеть и заставить переживать;

33. ...подарил Вам подарок или набор стикеров?

а) подарки лучше дарить по праздникам и более практичные, стикеры и подарки в социальных сетях - это лишняя трата денег;

38. ... Вы в общем диалоге написали свое мнение и стали камнем преткновения других участников и возникновением серьезного спора: одни критиковали Ваше мнение, а другие защищали?

а) очень неприятно, лучше бы я этого не делал, поссорил людей. Чувствую себя виноватым».

Для группы «художники» наиболее характерны такие групповые когнитивные механизмы, как групповая поляризация, предвзятость подтверждения. 
В комментариях к фотографиям и текстам респонденты этой группы чаще, чем другие, из любого события извлекают только подтверждение своей точки зрения. Среди «художников» различаются группы с диапазоном от незначительных повреждений целостности тела до тяжелых нарушений.

Среди индивидуальных когнитивных механизмов чаще встречаются эмоциональное обоснование и навешивание ярлыков ( $p \leq 0,05)$. В интернет-общении это выражается в кличках, негативных высказываниях.

У подростков, представленных в группе «зрители», среди групповых коммуникативных механизмов наиболее представлено отклонение в сторону позитивного исхода, индивидуальные когнитивные искажения статистически достоверно не выражены. Поведение этих подростков не имеет патологий. Однако, в силу выраженного интереса к группам с суицидальным контентом, мы сочли необходимым рассмотреть особенности и этой группы в данном исследовании.

\section{Обсуждение результатов}

Как показали результаты исследования, существуют отличия в выборе подростками групповых и индивидуальных когнитивных механизмов коммуникации в зависимости от группы суицидального поведения. Во-первых, требует понимания предмет коррекции - поведение или личность. В нашем случае мы настаиваем на психологической коррекции личности, учитывая сложность расшатывания неконструктивных когнитивных установок и замену неэффективных групповых и индивидуальных когнитивных механизмов более приемлемыми.

Вторым вопросом в дискуссии может стать вопрос о выборе методов психологической коррекции. Как показывает практика, педагоги чаще используют поощрение и наказание, однако, судя по количеству школьников с поведенческими девиациями, эти методы не являются эффективными. Мы предлагаем когнитивно-бихевиоральную коррекцию, в которой эти методы не будут единственными. В настоящий момент идет экспериментальное исследование, где проверяется наша система социально-психологического сопровождения. О результатах нами будет доложено после ее апробации.

Результаты исследования могут быть использованы педагогами и психологами для построения и апробации системы психологической профилактики и коррекции личности подростков с суицидальным поведением.

\section{Заключение}

Проведенное исследование позволило сделать выводы о характерных для подростков с разными типами суицидального поведения групповых и индивидуальных когнитивных механизмов коммуникации в интернет-пространстве. 


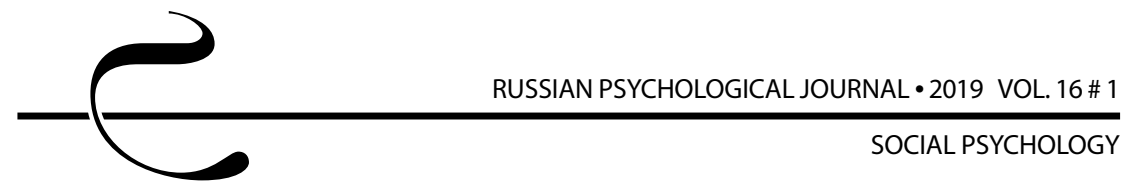

Так, для «суицидентов» основными групповыми механизмами коммуникации являются иллюзорная корреляция и искажение в оценке гомогенности группы, а индивидуальными - дихотомическое мышление и катастрофизация; для «имитаторов» групповыми - искажение в оценке гомогенности группы и предвзятость подтверждения, индивидуальными - персонализация и обесценивание позитивного; для «художников» групповыми механизмами стали групповая поляризация и предвзятость подтверждения, индивидуальными эмоциональное обоснование и навешивание ярлыков; «зрители» не имеют ярко статистически выраженных групповых и индивидуальных когнитивных механизмов общения.

Дальнейшего исследования требует динамика формирования суицидального поведения подростков в интернет-пространстве.

\section{Литература}

1. Абрумова А. Г. Анализ состояний психологического кризиса и их динамика // Психологический журнал. 1985. Т. 6, № 6. С. 107-115.

2. Веселовский К. С. Опыты нравственной статистики в России. СПб.: Тип. М-ва внутрен. дел, 1847.64 с.

3. Гилинский Я., Гурвич И., Русакова М. и др. Девиантность подростков: Теория, методология, эмпирическая реальность. Учебно-научное издание. СПб.: Медицинская пресса, 2001. 200 с.

4. Клейберг Ю. А. Психология девиантного поведения: учебник и практикум для вузов. М.: Юрайт, 2016. 290 с.

5. Личко А. Е. Суицидальное поведение подростков // Клинико-психологические социальные и правовые проблемы суицидального поведения. М., 1974. С. 71-79.

6. Александров А. А. Современная психотерапия. Курс лекций. СПб.: Академический проект, 1997. 335 с.

7. ЖезловаЛ.Я. Сравнительно-возрастные аспекты суицидального поведения у детей и подростков // Актуальные проблемы суицидологии. Труды Московского НИИ психиатрии. Т. 92. М., 1981. С. 124-133.

8. Вроно Е. М. О возрастном своеобразии аутоагрессивного поведения у психически здоровых подростков // Сравнительно-возрастные исследования в суицидологии. М.: Изд-во Моск. НИИ психиатрии, 1989. С. 39-46.

9. Булачель П. Ф. Самоубийство с древнейших времен до наших дней. Исторический очерк философских воззрений и законодательств о самоубийстве. СПб.: Паровая типо-литография, 1900. 206 с.

10. Демина Л. Д., Ральникова И. А. Психическое здоровье и защитные механизмы личности. Алтай: Изд-во Алтайского государственного университета, 2000. 123 с. 
11. Wenzel A. Group cognitive therapy of addictions / A. Wenzel, A. T. Beck. N.Y.: Guilford Press, 2012. 255 p.

12. Шапинский В. А. Девиантное поведение и социальный контроль: учебное пособие / В. А. Шапинский, В. И. Мареев. Ростов-на-Дону: Изд-во Ростовского государственного педагогического университета, 1997. 98 с.

13. СучковаМ.А.,ДаниловаМ. В. Особенности суицидального рискау подростков: анализ гендерных проявлений // Молодой ученый. 2014. № 8. С. 875-877.

14. Бек Дж. Когнитивная терапия: полное руководство: пер. с англ. М.: ООО «И.Д. Вильямс», 2006. 400 с.

15. Beck A.T., Freeman A. Cognitive therapy of personality disorders. New York: Guilford Press, 2003. 506 p.

16. BeckA. T.etal. An Inventory for Measuring Depression // Archives of General Psychiatry. 1961.4 (6). P. 561-571. DOI: $10.1001 /$ archpsyc. 1961.01710120031004

17. Clark D. A., Beck A. T. Scientific foundations of cognitive theory and therapy of depression. New York: Wiley, 1999. 504 p.

18. Gackenbach G. Psychology and the Internet: Intrapersonal, Interpersonal, and Transpersonal Implications. San Diego et al.: Academic Press, 2007. 392 p.

19. Riva G. Mind, cognition and society in the Internet age. Washington: IOS Press, 2001. $311 \mathrm{p}$.

20. Harris $R$. A cognitive psychology of mass communication. New Jersey: L. Erlbaum Associates, 2008. 464 p.

21. Donath J. Identity and deception in the virtual community // Communities in Cyberspace. 1999. P. 29-59.

22. Акулич М. М. Интернет-троллинг: понятие, содержание и формы // Вестник Тюменского государственного университета. Социально-экономические и правовые исследования. 2012. № 8. С. 47-54.

23. Arestova O., Babanin L., Voiskounsky A. Psychological research of computermediated communication in Russia // Behaviour \& Information Technology. 1999. Vol. 18, Issue 2. P. 141-147. DOI: 10.1080/014492999119174

24. Siegel J. Group Processes in Computer-Mediated Communication / J. Siegel, S. Kiesler // Behavior and Human Decision Processes. 1986. № 37. P. 157-187.

25. Шмаков А. А. Речевые тактики девиантного коммуникативного поведения пользователей сети Интернет // Экология языка и коммуникативная практика. 2015. № 1 (4). С. 293-305.

26. Лучинкина А. И. Суицидальная личность подростка в виртуальном пространстве // Педагогическое образование в изменяющемся мире. Казань: Отечество, 2017. С. 9-17.

27. Лучинкина А. И. Психологический анализ отклонений в процессе интернет-социализации личности // Гуманитарные науки (г. Ялта). 2016. № 1 (33). С. 54-62. 
28. Лучинкина А. И. Специфика мотивации интернет-пользователей // Перспективы Науки и Образования. 2014. № 6-12. С. 105-109.

29. Лучинкина И. С. Методологические проблемы исследования коммуникативного поведения пользователей в интернет-пространстве // Гуманитарные науки (г. Ялта). 2017. № 4 (40). С. 42-46.

30. Стернин И. А., Камбаралиева У. Д. Теоретические проблемы описания коммуникативного поведения // Коммуникативные исследования. 2018. № 2 (16). C. 20-34.

\section{References}

1. Abrumova A.G. The analysis of the psychological crisis conditions and their dynamics. Psikhologicheskii zhurnal, 1985, V.6, no. 6, pp. 107-115 (in Russian).

2. Veselovskii K. S. Opyty nravstvennoi statistiki v Rossii [Experience of moral statistics in Russia]. St. Petersburg, Tip. M-va vnutren. del Publ., 1847. 64 p.

3. Gilinskii Ya., Gurvich I., Rusakova M. Deviantnost' podrostkov: Teoriya, metodologiya, empiricheskaya real'nost' [Adolescent deviance: Theory, methodology, and empirical reality]. St. Petersburg, Meditsinskaya pressa Publ., 2001. 200 p.

4. Kleiberg Yu. A. Psikhologiya deviantnogo povedeniya [Psychology of deviant behavior]. Moscow, Yurait Publ., 2016. 290 p.

5. Lichko A. E. Suicidal behavior among adolescents. Kliniko-psikhologicheskie sotsial'nye i pravovye problemy suitsidal'nogo povedeniya - Clinical and Psychological Social and Legal Issues of Suicidal Behavior, Moscow, 1974, pp. 71-79 (in Russian).

6. Aleksandrov A. A. Sovremennaya psikhoterapiya [Modern psychotherapy]. St. Petersburg, Akademicheskii proekt Publ., 1997. 335 p.

7. Zhezlova L. Ya. Comparative age aspects of suicidal behavior in children and adolescents. Aktual'nye problemy suitsidologii. Trudy Moskovskogo NII psikhiatrii - Actual problems of suicidology: Proceedings of the Moscow Institute of Psychiatry, V. 92, Moscow, 1981, pp. 124-133 (in Russian).

8. Vrono E. M. Age-related specific characteristics of auto-aggressive behaviour in mentally healthy adolescents. In: Sravnitel'no-vozrastnye issledovaniya $v$ suitsidologii [Comparative and age-related studies in suicidology]. Moscow, Moscow Institute of Psychiatry Publ., 1989, pp. 39-46.

9. Bulatsel' P. F. Samoubiistvo s drevneishikh vremen do nashikh dnei. Istoricheskii ocherk filosofskikh vozzrenii i zakonodatel'stv o samoubiistve [Suicide from ancient times to the present day: A historical sketch of the philosophical views of suicide and legislations]. St. Petersburg, Parovaya tipo-litografiya Publ., 1900. 206 p. 
10. Demina L. D., Ral'nikova I. A. Psikhicheskoe zdorov'e i zashchitnye mekhanizmy lichnosti [Mental health and defence mechanisms of the person]. Altai, Altai State University Publ., 2000. 123 p.

11. Wenzel A. Group cognitive therapy of addictions. N.Y., Guilford Press, 2012. $255 \mathrm{p}$.

12. Shapinskii V. A. Deviantnoe povedenie i sotsial'nyi kontrol' [Deviant behavior and social control]. Rostov-on-Don, Rostov State Pedagogical University Publ., 1997. 98 p.

13. Suchkova M. A., Danilova M. V. Characteristics of adolescent suicide risk: An analysis of gender manifestations. Molodoi uchenyi - Young Scientist, 2014, no. 8, pp. 875-877 (in Russian).

14. Beck J. Cognitive therapy. Moscow, I.D. Vil'yams Publ., 2006. 400 p.

15. Beck A. T., Freeman A. Cognitive therapy of personality disorders. New York, Guilford Press, 2003. 506 p.

16. Beck A. T. et al. An inventory for measuring depression. Archives of General Psychiatry, 1961,4(6),pp.561-571.DOI:10.1001/archpsyc.1961.01710120031004

17. Clark D. A., Beck A. T. Scientific foundations of cognitive theory and therapy of depression. New York, Wiley, 1999. 504 p.

18. Gackenbach G. Psychology and the Internet: Intrapersonal, interpersonal, and transpersonal implications. San Diego et al., Academic Press, 2007. 392 p.

19. Riva G. Mind, cognition and society in the Internet age. Washington, IOS Press, 2001. $311 \mathrm{p}$.

20. Harris R. A cognitive psychology of mass communication. New Jersey, L. Erlbaum Associates, 2008. 464 p.

21. Donath J. Identity and deception in the virtual community. Communities in Cyberspace, 1999, pp. 29-59.

22. Akulich M. M. Internet trolling: Concept, content, and forms. Vestnik Tyumenskogo gosudarstvennogo universiteta. Sotsial'no-ekonomicheskie i pravovye issledovaniya - Bulletin of Tyumen State University: Socio-Economic and Legal Research, 2012, no. 8, pp. 47-54 (in Russian).

23. Arestova O., Babanin L., Voiskounsky A. Psychological research of computermediated communication in Russia. Behaviour \& Information Technology, 1999, V. 18, Issue 2, pp. 141-147. DOI: 10.1080/014492999119174

24. Siegel J. Group processes in computer-mediated communication. Behavior and Human Decision Processes, 1986, no. 37, pp. 157-187.

25. Shmakov A. A. Speech tactics of deviant communicative behavior of Internet users. Ekologiya yazyka i kommunikativnaya praktika - Ecology of Language and Communicative Practice, 2015, no. 1 (4), pp. 293-305 (in Russian).

26. Luchinkina A. I. Suicidal personality of adolescents in the virtual space. Pedagogicheskoe obrazovanie $v$ izmenyayushchemsya mire - Pedagogical 
Education in a Changing World. Kazan, Otechestvo Publ., 2017, pp. 9-17 (in Russian).

27. Luchinkina A. I. Psychological analysis of deviations in the process of Internet socialization. Gumanitarnye nauki - Humanities (Yalta), 2016, no. 1 (33), pp. 54-62 (in Russian).

28. Luchinkina A. I. Specific character of Internet users' motivation. Perspektivy Nauki i Obrazovaniya - Perspectives of Science and Education, 2014, no. 6-12, pp. 105-109 (in Russian).

29. Luchinkina I. S. Methodological problems in the study of the communicative behaviour of Internet users. Gumanitarnye nauki - Humanities (Yalta), 2017, no. 4 (40), pp. 42-46 (in Russian).

30. Sternin I. A., Kambaralieva U. D. Theoretical issues in the description of communicative behavior. Kommunikativnye issledovaniya-Communication Research, 2018, no. 2 (16), pp. 20-34 (in Russian). 